\title{
Faculdade de Educação: antecedentes e origens
}

BEATRIZ A. DE MOURA FÉTIZON

A implantaçăo dos estudos de educação na Universidade de São Paulo e seu desenvolvimento ao longo de todo o período de por três ordens de equívocos, longamente reiterados: deficiência estrutural, percepção dos estudos de educação como estudos superiores de segunda categoria e manipulação dos cursos pedagógicos com vistas a objetos estranhos à área de educaçáo.

\section{A reiterada deficiência estrutural}

Em sua origem, creio estar um equívoco de equacionamento fins/meios.

Para os fundadores, a criação da USP respondeu a uma necessidade e a uma conviç̧ão: necessidade de reconquistar a liderança política do estado na federação; e conviç̧áo de que o caminho para tanto seria a conquista da liderança cultural, mediante um sério programa educacional. Júlio de Mesquita Filho é taxativo: "(...) O problema brasileiro era (...) de cultura (...)". Atribuída "à série infinita de erros praticados dentro das fronteiras de nosso estado pela ditadura à mentalidade primária de seus prepostos, não pareceria menos evidente que só uma reforma radical do aparelhamento escolar e a instaurafáo de uma rigorosa política educacional poderia epitar a catástrofe final. (...) Vencidos pelas armas (...) paulistas até a medula (...) que maior monumento poderíamos erguer aos que haviam consentido no sacrifício supremo para preservar contra o vandalismo que acabava de aviltar a obra de nossos maiores, das bandeiras à independência e da Regência à República do que a Universidade?" (1).

Ora, com a criação da USP, os estudos de educaçáo, no estado de Sáo Paulo, ficaram assim distribuídos: fora da universidade, nas escolas normais, a formação de professores primários; e, numa beiradinba (ou num desvio) da universidade - na Escola de Professores do Instituto de Educaçáo de Sáo Paulo (Caetano de Campos) (2) - a formaçáo de professores secundários. Quanto aos alunos teóricos de educaçáo, fica- 
ram fora do desvio, no lugar nenhum. Ou seja, a universidade que se criava para salvar a pátria (literalmente, é o caso de se dizer) pela educação não abrigava, senão tangencialmente, os estudos educacionais em geral e a formação de professores em particular. E sua Faculdade de Filosofia, Ciências e Letras, que seria o eixo de todo o projeto, a unipersidade dentro da unipersidade, o instituto propriamente unipersitdrio que, integrando o novo organismo pela base, lhe conferiria o estatuto de universidade por abrigar todos os ramos "de investigaçáo científica, de altos estudos, de cultura livre e desinteressada" (para usar os termos do decreto de fundação) regendo-se pelo princípio da unidade do conhecimento e da formação intelectual, fundamento indispensável aos estudos profissionais promovidos pelas demais unidades - precisamente ela, não acolhia os estudos de educação.

Assim, se de um lado, detectou-se claramente o probema educacional no cerne da questão política (e não cabe aqui discutir a pertinência desta percepção, mas apontar a inadequação fim/meios), não se considerou, por outro lado, senão perifericamente, a própria questão educacional. $\mathrm{E}$ isto nos conduz ao segundo equívoco.

\section{A reiterada percepção dos estudos de educação como estudos superiores de segunda categoria}

A trajetória dos estudos de educação até sua incorporação à universidade (na década de 30) foi acidentada. Restringir-me-ei a seus marcos principais, nos âmbitos federal/nacional e paulista.

Em São Paulo, a reforma Sampaio Dória, de 1920 (Lei estadual no 1750), cria uma Faculdade de Educaçáo (estrutura administrativa e didática) que não chega a ser implantada, mas revela a influência de Georges Dumas e seu projeto de uma Escola Normal Superior, inspirado no modelo francês. Em 1926 a questão da educação ganha destaque com o inquérito de $O$ Estado de $S$. Paulo, dirigido por Fernando de Azevedo (3).

À mesma época, partindo do Rio de janeiro, amplo movimento conjuga esforços de membros de diversas entidades - Politécnica do Rio, Academia Brasileira de Ciências (ABC), Associaçáo Brasileira de Educaçăo (ABE), Institutos Franco-Brasileiros de Alta Cultura, e imprensa (destaque para O Estado de S. Paulo) - com vistas à reforma do ensino superior segundo uma nova concepçáo, que fazia da pesquisa básica o eixo e o cerne da universidade.

Os debates da ABC, em 1923, reivindicando a Escola Superior de Ciências, dedicada à ciencia pura oficializam a tomada de posiçáo. A 
vinda de Einstein, em 1925, culminando os esforços (e acirrando as disputas) da $\mathrm{ABC}$ e dos neo-positivistas da Poli-Rio pela aceitaçáo da nova física, eleva a temperatura dos debates. $O$ intercâmbio entre o Franco-Brasileiro do Rio e a $\mathrm{ABC}$, promovendo a vinda ao Brasil de cientistas e pensadores $\mathrm{e}$ a ida de alguns dos expoentes brasileiros desse movimento para ministrar cursos na Universidade de Paris como professores convidados (Amoroso Costa, entre outros), alimenta as discussóes sobre os novos rumos do ensino superior.

As questōes relativas aos estudos de educação entrarão nesse debate graças à peculiar circunstância da fundação da $\mathrm{ABE}, \mathrm{em} 1924$, por inspiraçăo de Heitor Lira da Silva (da Poli-Rio) que traz para a nova entidade os mais importantes líderes do movimento da $\mathrm{ABC}$ e da Politécnica, colocando-os à frente da seção de Ensino Técnico e Superior, à qual incumbiam as questóes relativas à universidade. A seçáo, e seus líderes, estiveram na vanguarda das primeiras Conferências Nacionais de Educaçáo (que, até 1930, foram eventos da maior importância para o ensino superior brasileiro) e dos inquéritos de 1927, da ABE - um deles voltado exclusivamente para o ensino superior (e cujo relatório final incorporou boa parte do $2^{\circ}$ inquérito de $O$ Estado de $S$. Paulo), sem esquecer o Congresso do Ensino Superior de 1927.

Sobrevindo 1930, o governo central edita o Estatuto das Universidades Brasileiras (Reforma Francisco Campos, Decretos federais nos 19851 e 19832/31) que se propóe, consoante o estilo centralizador do novo regime, como padráo nacional.

Por razōes cuja discussão aqui năo cabe (a exposição de motivos é muito elucidativa a respeito), o modelo brasileiro coloca, no eixo da universidade, não uma Faculdade de Filosofia Ciência e Letras (como o faria a USP) mas uma Faculdade de Educafacio, Ciências e Letras. Embora por razóes diversas, também a UDF, de Anísio Texeira, centraria a universidade numa Faculdade de Educaçáo. Além disso, o Estatuto eleva a nível superior a formaçáo do professor secundário.

Enquanto isso, em São Paulo (não obstante os avanços das primeiras décadas republicanas e os acenos da reforma de 1920), os estudos de educação sofriam percalços que caracterizam bem uma condição de desprestígios.

Em fevereiro de 1931, o Decreto estadual no 4888 reforma a Escola Normal da Praça (Caetano de Campos), transformando-a em Instituto Pedagógico e nele criando o curso de aperfeiçoamento para a "preparaçáo técnica de inspetores, delegados de ensino, diretores de estabelecimentos e professores do curso normal". E, apesar do que disporá 
dois meses depois o Estatuto Federal (abril de 31), somente em 1933 se tomam medidas, no estado, para elevar em nível superior a formação do professor secundário. Nesse ano, os Decretos nos 5846 e 5844 (reforma do Instituto Pedagógico que se transforma em Instituto de Educação, e Código da Educaçáo) criam, finalmente, os estudos superiores da educaçáo no estado de São Paulo. No Instituto de Educação, o curso de aperfeiçoamento sofre acréscimo: uma nova seção, dita Escola de Professores, destinada à formaçáo pedagógica dos candidatos ao magistério secundário. Os conteúdos específicos das disciplinas que pretendessem lecionar ficariam a cargo de uma futura Faculdade de Ciencias e Letras (4) - se e quando fosse criada. E, por força do Decreto federal, essa escola de professores (e só ela no curso de aperfeiçoamento) seria em nível superior.

Era, porém, um nipel superior muito distante daquele das faculdades instaladas: já por sua duração, já por funcionar em escola de nível médio e, por acréscimo, com um corpo docente sem formaçáo superior. O próprio Código de Educação diferencia este ensino bibrido (médio e superior) isolando-o. No artigo $1^{\circ}$, sáo tratados separadamente (alíneas b e $i)$ a "educaçáo pedagógica de grau superior ministrada em dois ou três anos na Escola de Professores do Instituto de Educação" e a "educação profissional de grau superior ministrada nas Faculdades em cursos de quatro e seis anos". E o artigo $2^{\circ}$ subordina as Faculdades diretamente à Secretaria de Educação, permanecendo o ensino superior do Instituto, juntamente com as escolas primárias, normais e secundárias, subordinado ao Departamento de Educação.

Ao criar-se a USP, a circunstância de já existir um curso superior de formação de professores secundários (satisfazendo à exigência federal) vem a calhar para viabilizar a pariante paulista (5): mantém-se o núcleo da universidade (Fáculdade de Filosofia) tal como previsto, e incorpora-se ao setor profissional a pequena faixa do Instituto de Educação que fornecia a formaçăo pedagógica para o magistério secundário.

Se isto representou um acréscimo de status para a dita Escola de Professores, o mesmo năo ocorreu para os estudos de educaçáo. De uma lado, a Faculdade de Filosofia não os acolhem; de outro, a duração dos cursos da escola e a formação média de seus professores continuavam intocadas.

A incorporação da Escola de Professores à Faculdade de Filosofia, quatro anos mais tarde, só veio piorar a situação. Em primeiro lugar, a formaçáo pedagógica do professor secundário cai de dois ou três anos 
para 180 horas (significando que o tăo referido esquema $3+1$ não passava de $3+1 / 4$ ) Ademais, os professores incorporados com o acerno da escola (materiais, biblioteca, arquivos, alunos e mestres), em sendo efetivos, tornam-se os primeiros catedráticos da Faculdade de Filosofia (em que vigia a moratória de cátedra). Isto criará situaçóes, no mínimo, desconfortáveis do ponto de vista acadêmico e administrativo - catedráticos sem formaçáo superior ombreando-se com mestres estrangeiros (haja vista a composição da congregação e dos órgáos superiores). $O$ que ocorreu não facilitou as coisas para os estudos de educação.

Fatos e circunstâncias testemunham esta condiçáo de desprestígio da seção de Pedagogia (em que se transformara a Escola de Professores). Abreviando, lembrarei simplesmente que, salvo raríssimas exceçōes (Noemi Silveira Rudolfer e sua Psiocologia da Educação são uma delas), as disciplinas e respectivos catedráticos que, vindos do Instituto de Educaçáo, conseguiram destaque e maior reconhecimento na Faculdade (e na Universidade), fizeram-no incorporando-se a alguma das Seçóes originárias e perdendo seus qualificativos educacionais (Antunha lembra, entre outros, os casos de Sociologia, com Fernando de Azevedo e de Estatística com Milton S. Rodrigues).

Poderíamos rastrear mais longamente o fenômeno. Não há espaço. Mas esse desprestígio é, também, sem dúvida, um dos fatores do terceiro equívoco.

\section{Reiterada manipulação dos cursos pedagógicos na Universidade}

O modelo originário da USP, que conserva até hoje recursos de inegável atualidade, não chegou a ser implantado em seus aspectos mais peculiares e significativos. A primeira fase de sua vigência (1934 a 1939) é marcada pelas reiteradas tentativas de implantá-lo - e os principais problemas enfrentados se ligam à Faculdade de Filosofia. Dificuldades estruturais e conjunturais.

Dentre as conjunturais, destacarei três ordens de ocorrências que se refletiráo sobre os rumos da USP e, no seu interior, sobre os estudos pedagógicos. Em primeiro lugar, os reflexos da política centralizadora pós-30: a Lei no 452, de 5/7/37 que, organizando a Universidade do Brasil, a institui como padráo nacional; os sucessivos atos do Estado Novo que centralizam e uniformizam as estruturas didática e administrativa das instituiçōes de ensino superior, seu funcionamento, seus currículos e o reconhecimento de graus e títulos. A seguir, duas medidas 
estaduais incidindo diretamente sobre os cursos de educação na USP: os decretos nos 9268 A e 9403 - de julho e agosto de 1938 - que extinguem o Instituto de Educação da USP e criam, na Faculdade de Filosofia, uma quarta seçáo - a de Pedagogia. E, finalmente, o Decreto-lei n 1190, de 4/4/39 que, organizando a Faculdade de Filosofia da UB, padroniza, por ela, todas as demais, conferindo-lhes objetivo profissionalizante - com ênfase na preparação dos quadros do magistério - $\mathbf{e}$ exigindo (artigo 51) o diploma de licenciado para o preenchimento de cargos e funções do magistério secundário e normal (redes pública e particular).

Quanto às principais dificuldades estruturais, já o decreto de fundação permite inferir que eram previstas e temidas (o documento é uma obra-prima de omissóes diplomáticas e de vias indiretas na instituiçâo de medidas que pudessem ferir brios ou provocar resistência). Os fatos demonstraráo o acerto de tais previsóes e cuidados. E revelarão, ademais, um grave erro de avaliação: as dificuldades se confiruram muito maiores do que o esperado.

A primeira delas (e o primeiro erro de avaliaçáo) concerne à capacidade de resistência das unidades já instaladas (resistência fundada em poder e prestígio consolidados) quando se tratou de submeterem-se à nova ordem. $\mathrm{Na}$ esfera administrativa, uma acomodaçáo, embora lenta, foi possível. Na ordem didática, os entraves foram definitivos.

Para cumprir sua funçáo de asseguradora do nível universitário da USP, via integração e qualidade, a Faculdade de Filosofia fora dotada de equipamentos e corpo docente que lhe permitissem produzir ampla diversidade e alta qualidade de pesquisa, assumir as cadeiras gerais ou básicas de todas as demais unidades, e subsidiar a formação e $o$ aperfeiçoamento dos respectivos corpos docentes (6).

As chamadas trés grandes - Direito, Medicina e Politécnica reagiram violentamente à extinçăo de cadeiras e à centralização das respectivas disciplinas na Faculdade de Filosofia, medidas que entenderam configurar perda de prestígio, de poder e de cargos (no que provavelmente tinham razão). Os conflitos evoluíram para violentas disputas envolvendo Congregaçóes, Reitoria, Conselho Universitário e Conselho Nacional de Educação. Da Politécnica, os filósofos (mestres e alunos de Física) foram expulsos (por alunos e mestres) à mão armada... de paus e cadeiras. Da Faculdade de Direito os filosofos não chegaram a ser expulsos - sequer haviam conseguido entrar (é verdade que uma das cadeiras a serem extintas - Economia Política - era a do interventor do estado...). Bem, isto, a título de exemplo. 
O que importa é que, sem ter conseguido se instalar para as funçóes previstas - e que utilizavam sua capacidade de trabalho em todas as Unidades da Universidade - a Faculdade de Filosofia viu-se reduzida aos cursos de bacharelado, voltados para a pesquisa básica, "os altos estudos e o saber desinteressado" e esteve a pique de fechar por falta de alunos, em 1937 (vide, entre outros, Fernando de Azevedo, Ernesto de Souza Campos e Eurípedes Simóes de Paula). É preciso convir que, à época, a demanda por investigadores em ciências matemáticas naturais ou humanas, e mesmo em letras, não era de molde a favorecer as matrículas.

E vem a salvaçáo, por obra da política centralizadora do Estado Novo. Extinta a Escola de Professores, criada a seçáo de Pedagogia na FFCL e exigia a licenciatura para o exercício de cargo ou função nas redes pública e particular ao ensino secundário e normal, a Faculdade que quase fechara por falta de alunos (e cujos mestres estrangeiros, ociosos, estavam sendo alocados em ocupaçóes provisórias e paralelas) passa, muito rapidamente, a ser a mais numerosa unidade da Universidade.

Com isso se encerravam duas coisas: a primeira crise da USP e as tentativas de se implantar o modelo chamado puro. Decorrerão daí conseqüências importantes, tanto para a Faculdade de Filosofia (7) quanto para os estudos de Educação. Só aludirei a estas últimas.

Descomprometida, por suas origens, com os estudos de educação, a Faculdade de Filosofia não se reestruturou para incorporá-los. A pedagogia simplesmente se acrescentou à estrutura original como adendo anódino que em nada alterou os procedimentos didáticos. A vocação, 0 projeto e as práticas eram os bacharelados. $\mathrm{E}$ continuaráo sendo. As licenciaturas foram o oportuno recurso de sobrevivência. E foi só. Ou não, não foi. Houve ainda uma segunda grande manipulação.

A universidade crescia - embora muito aquém do crescimento da procura. A Faculdade de Filosofia era a grande válvula de escape da demanda excedente. Em 1960, para 8.236 inscritos no vestubular, a USP oferecia 2.115 vagas, das quais 735 na FFCL (mais de $1 / 3$ do total). Em, 1969, os inscritos eram 31.984 (o pico fora em $68 \mathrm{com}$ 34.282 ) e as vagas totais 5.804 , com 2.800 na FFCL (mais da metade do total e mais de $2 / 3$ das demais juntas).

Os setores mais poderosos e prestigiados fecharam-se em estreito numerus clausus em nome da qualidade do ensino. E a Universidade manipula o fluxo de vagas canalizando-o para os setores menos capazes de resistir, inchando-os pelo desdobramento artificial de opçóes. De 
novo, as licenciaturas foram um expediente precioso: unificaçăo de vestibulares por áreas, opçóes, múltiplas e criação indiscriminada de licenciaturas em disciplinas inexistentes no ensino médio, funcionaram a contento. Mas por tal forma incharam a FFCL e agravaram empurrando-a para um nebuloso processo de desmembramento e extinção (8).

Nesse desmembramento, a antiga seçáo de Pedagogia - já, entáo, Departamento - consegue reencontrar-se - por vias transversas com o projeto de que estivera extraviada desde os longíquos anos 20: torna-se unidade autônoma, a Faculdade de Educaçáo.

Sua criação se dá por força dos Estatutos da USP editados pelo Decreto Estadual 32.305, de 16/12/69 e seu funcionamento data de 1 은 de janeiro de 1970.

\section{Notas}

1 Segundo o reitor Ulhôa Cintra (discurso de posse, 15.05.60), recém-empossado na Interventoria, Armando de Salles Oliveira perguntara a Júlio de Mesquita Filho o que faria no governo do estado, face aos problemas de entáo. Da resposta de Júlio de Mesquita nasceram a USP e sua FFCL.

2 Ela mesma sendo uma pequena seçăo do curso de Aperfeiçoamento do Instituto de Educaçăo.

3 Este é o segundo inquérito do mesmo jornal (o primeiro fora o de 1914)

4 Expressăo usada pelo decreto, contornando as disputas entre duas correntes quanto à soluçăo a ser adotada pela USP: Fillosofia ou Educafán, Ciências e Letras.

5 Segundo o EUB seriam critérios de organizaçäo das universidades, "os reclamos e necessidades do pals" (artigo 2\%); por isso, o artigo $3^{\circ}$ admitia "variantes regionais" dos preceitos contidos no presente decreto (...) no que respeita à administraça e aos modelos didáticos".

$6 \mathrm{Bm}$ Polistica e cultura, Júlio de Mesquita Filho traça um perfil severo da qualidade do ensino superior já instalado (exceçáo para Medicina).

7 Vide Antunha (1974) e Eurípedes Simóes (Discurso de Paraninfo, FFCL, turma de 1951)

8 Processo que envolveu interesses internos e externos à universidade: medo (dentro e fora da USP) da subversåo e da capacidade de contestaçăo acumulada na táo perigosa, em que se transformara a criatura dos fundadores - que há muito adquirira vida própria e escapara ao controle do criador (para usar as metáforas de Florestan Fernandes); demanda pela cátedra represada (14 categorias e subcategorias de docentes e fantasioso desdobramento de disciplinas correspondendo às diferenças dos respectivos regentes); congestionamento na ante-sala dos postos administrativos. Tudo se resolvia. Pulveriza-se a contestaçăo antes que seja rearticulada no pós-cassaģoes. Desdobram-se as direçöes, as administraçōes, as congregaçōes, as representaçóes nos colegiados superiores, as cátedras etc. 


\section{Referências Bibliográficas}

ANTUNHA, H.C.G. As origens da Faculdade de Educação. Revista da Faculdade de Educagrno, São Paulo, FEUSP, v. 1, n. 1, p: 225-242, 1975.

Universidade de São Paulo: fundação e reforma. São Paulo, CRPE, Estudos e Documentos, v. 10, 1974.

CAMPOS, E.A. História da Universidade de Săo Paulo.São Paulo, USP, Reitoria, 1954.

Educação Superior no Brasil. Rio de Janeiro, Rev. Ed., 1940.

Estudos sobre o problema unipersittiria São Paulo, Empresa Gráfica da Revista dos Tribunais, 1930.

UM CONFLITO entre a Congregação da Escola Politécnica e o Conselho Univeristário da Universidade de São Paulo, perante o Conselho Nacional de Educaçāo. São Paulo. Empresa Gráfica da Revista dos Tribunais, 1937.

FÉTIZON, B.A.M. Educar professores? (Um questionamento dos cursos de licenciatura da USP). Săo Paulo, FEUSP, Ertudos e Documentos, v. 24, 1978.

Substios para o estudo da Unipersidade de Säo Paulo. Tese de Doutoramento. Dat. Bibl. FEUSP.

AZEVEDO. F.A. A eduscafắo na encruzilhada. $5^{\text {a }} \mathrm{ed}$. São Paulo, Melhoramentos, 1960.

Na batalha do humanismo. 5ª ed. São Paulo, Melhoramentos, 1967.

MESQUTTA FILHO, Júlio de. Política e Cultura. São Paulo, Martins, 1969.

Beatriz A. de Moura F́trizon é professora da Faculdade de Educaçāo da USP. 